\title{
ВЛИЯНИЕ ОСВЕЩЕНИЯ НА ВРЕМЯ ЯЙЦЕКЛАДКИ И КАЧЕСТВО КУРИНЫХ ЯИЦ \\ (обзор)
}

\author{
А.Ш. КАВТАРАШВИЛИ1, В.И. ФИСИНИН1, В.С. БУЯРОВ 2 , \\ Т.Н. КОЛОКОЛЬНИКОВА ${ }^{3}$
}

\begin{abstract}
Яйцекладка - сложный процесс, в котором время яйцекладки (ВЯ), цикл яйцекладки (ЦЯ) и интервал яйцекладки (ИЯ) взаимообусловлены (B.G. Roy с соавт. 2014). Настоящий обзор посвящен оценке влияния освещения на время яйцекладки и его связи с показателями качества яиЦ и продуктивностью кур (Gallus gallus domsticus L.). ВЯ напрямую сопряжено со временем овуляции, которое, в свою очередь, зависит от времени пикового выброса лютеинизирующего гормона в кровь передним отделом гипофиза (S.C. Wilson с соавт., 1984). В стандартных 24-часовых свето-темновых циклах при однократном чередовании света и темноты яйцекладка происходит в основном за световой период (F. Noddegaard, 1998; Г.А. Кирдяшкина с соавт. 2009), а при режимах прерывистого освещения ассиметричного типа - в течение «субъективного дня» (P.D. Lewis с соавт., 1990; А.Ш. Кавтарашвили с соавт. 2002; А.Ш. Кавтарашвили, 2007). Снесение большей части яиц от суточного сбора происходит примерно через 5-6 ч после включения света (A.H. Zakaria, 2005), что соответствует среднему ВЯ через 13-15 ч после наступления темноты (K. Lillpers, 1991; P.H. Patterson, 1997; R.J. Etches, 1990; А.Ш. Кавтарашвили с соавт., 2019). Среднее ВЯ определяется в результате сложного взаимодействия сигналов времени «рассвета» и «заката» при превалирующем влиянии последнего (S.S. Liou с coaвт., 1987; B.M. Bhati, с соавт., 1988). Увеличение продолжительности свето-темнового цикла на 1 ч (в циклах 24-30 ч) при одинаковой продолжительности фотопериода приводит к сокращению среднего Вя на 1,89-1,90 ч. Удлинение же продолжительности темнового периода на 1 ч внутри каждого цикла сдвигает ВЯ на 0,26-0,27 ч в сторону «заката». ВЯ влияет на качество яиц. Так, масса яиц, снесенных утром, выше, чем снесенных в более поздний период (Е. Tůmová с coaвт., 2010; M. Akif Boz с соавт., 2014; S. Samiullah с соавт., 2016; А.J. Kryeziu с соавт., 2011). В одних исследованиях (R.H. Harms, 1991; E. Tůmová с соавт., 2009) масса, толщина и прочность скорлупы были лучше у утренних яиц, в других (Е. Tůmová с соавт., 2005, 2007; А.J. Kryeziu с соавт., 2011; C. Hrnčár c coaвт., 2013) - в середине дня. У утренних яиц выше интенсивность коричневой окраски (S. Samiullah с соавт., 2016; А.J. Kryeziu с соавт. 2011) и содержание кальция в скорлупе (Е. Tůmová с соавт. 2014), но ниже содержание холестерина (на 22,8 \%) (Е. Tůmová с coавт., 2008; М.A. Abdalla с соавт. 2018), фосфора и магния (Е. Tůmová с соавт. 2014), чем у полуденных яиц. Куры, характеризующиеся ранней по времени яйцекладкой, имеют более длинный ЦЯ и более продуктивны по сравнению с теми, которые несутся в более позднее время дня. Величина коэффициента наследуемости $\left(\mathrm{h}^{2}\right)$ ВЯ находится в диапазоне от 0,38 до 0,78 (K. Lillpers, 1991). Существует положительная коррелятивная связь $(r=0,54)$ между продолжительностью ЦЯ и яйценоскостью (М. Bednarczyk с соавт., 2000; Р. Miandmients с соавт., 1993). В связи с вышеизложенным целесообразно и перспективно включать показатель среднего ВЯ и длины ЦЯ в программу селекции по улучшению яичных и мясных кроссов. Кроме того, оптимизация ВЯ позволит рационализировать сбор яиц и улучшить их качества на птицефабриках. Влияние освещения на ВЯ и качество яиц изучалось в основном при постоянном освещении. Необходимы углубленные исследования в условиях прерывистого светового дня как при индивидуальном (с учетом порядкового номера яиц в ЦЯ), так и при групповом содержании кур.
\end{abstract}

Ключевые слова: Gallus gallus domesticus, куры-несушки, освещение, время яйцекладки, качество яиц.

Внедрение в практику интенсивного птицеводства безоконных птичников значительно повысило роль освешения в технологии производства яиц и расширило возможности разработки и применения режимов освещения для регулирования полового созревания птицы, суточного ритма яйцекладки и качества яиц, повышения продуктивности кур. Настоящий обзор посвящен оценке влияния освещения на время яйцекладки и его связи с показателями качества яиц и продуктивностью кур.

Механизм роста, развития и овуляции яйцеклеток, образования и снесение яйца. Куры современных яичных кроссов могут производить более 330-340 яиц в год $(1,2)$. В яичнике 1-суточного 
цыпленка присутствует 3500-12000 фолликулов, то есть значительно больше, чем курица сносит за свою жизнь (2-4). По структуре фолликулы представляют собой яйцеклетку с оболочкой без желтка. С наступлением половой зрелости они последовательно увеличиваются (5). Рост, созревание и овуляция яйцеклетки, а также образование и снесение яиц детерминированы геномом кур и зависят от скоординированного действия гормонов гипоталамуса, гипофиза и яичника при взаимодействии с условиями окружающей среды $(2,6)$. Фолликулярное развитие в репродуктивном процессе кур-несушек включает две основные группы фолликулов. Первая группа предиерархическая, в которую входят мелкие белые (менее 2 мм), крупные белые (2-4 мм) и мелкие желтые фолликулы (4-8 мм). Вторая группа иерархическая, формируется 5-7 крупными желтыми быстрорастущими фолликулами (9-35 мм), которые достигают преовуляторного размера за 710 сут (7). Чем меньше крупных фолликулов в иерархической группе, тем быстрее в них накапливается желток и созревает яйцеклетка (2). Каждый из фолликулов, принадлежащих к иерархической группе, идентифицируется уменьшающейся цифрой в зависимости от его размера (самый большой фолликул $\mathrm{F}_{1}$, второй $-\mathrm{F}_{2}$, третий $-\mathrm{F}_{3}$ и т.д.). Как только фолликул входит в иерархическую категорию, он не может страдать атрезией (8). Каждый раз овулирует самый большой фолликул, а новый для входа в иерархию набирается из предиерархических мелких желтых фолликулов (6).

После овуляции яйцеклетка-желток, выделившаяся из самого крупного фолликула, захватывается воронкой яйцевода и при дальнейшем продвижении по нему подвергается последовательным отложениям на ней остальных компонентов (белка и скорлупы) яйца (9). Продолжительность формирования яйца в яйцеводе обычно составляет 22,5-26,2 ч, в том числе в воронке - 20-30 мин, белковом отделе - 2-3,2 ч, перешейке -1 -1,3 ч, матке - 16-21 ч (в среднем - 18-19 ч) (2, 4, 10-12). Процесс образования белка длится 3,25-3,5 ч $(3,13)$. Самый долгий этап образования яйца формирование яичной скорлупы занимает до 19-20 ч. Оно начинается через 4,5-5 ч после овуляции и заканчивается за 1,5 ч до снесения яйца. Конечным результатом становится полноценное яйцо $(3,13)$. После снесения яйца очередная овуляция происходит через 15-45 мин. У высокопродуктивных кур цикл овуляции (период между двумя последовательными овуляциями) длится почти 24 ч, в то время как у низкопродуктивной птицы он может занять 24-27 ч $(9,14)$. Чем короче средний интервал, тем длиннее цикл яйцекладки и выше яйценоскость птицы (15).

За 4-6 ч до овуляции в крови резко повышается содержание лютеинизирующего гормона (ЛГ, гормон передней доли гипофиза), который, в свою очередь, стимулирует секрецию прогестерона (гормона преовуляторного фолликула). ЛГ регулирует распад соединительных тканей в области стигмы фолликула, разрыв стенки фолликула и выход яйцеклетки (13). F. Croze c соавт. (16) предположили, что преовуляторное высвобождение тестостерона оказывает подготовительное действие на гипоталамогипофизарно-яичниковую систему и тем самым облегчает преовуляторное высвобождение ЛГ. В проведенных позже исследованиях было установлено, что блокирование действия тестостерона его специфическим антагонистом флутамидом приводит к остановке преовуляторного всплеска плазменного тестостерона, прогестерона, эстрадиола, ЛГ и, следовательно, прогнозируемой яйцеклетки у кур-несушек (17).

Яйцекладка - сложный процесс, в котором время яйцекладки (ВЯ, среднее по стаду время суток, когда куры сносят яйца), цикл яйцекладки (ЦЯ, период, в течение которого птицы сносят яйца ежедневно) и интер- 
вал яйцекладки (ИЯ, период между двумя последовательными циклами яйцекладки) взаимосвязаны (18). Известно, что время яйцекладки зависит от генотипа, системы содержания, возраста (18), времени кормления птицы $(19,20)$, режима освещения $(21)$, температуры в птичнике (22). Как свидетельствуют данные литературы, наиболее существенное влияние на время снесения яиц у кур оказывает освещение.

Время яйцекладки напрямую связано со временем овуляции, которое, в свою очередь, зависит от выброса лютеинизирующего гормона (ЛГ) передним отделом гипофиза (23). Предовуляторный выброс ЛГ у несушек продолжается около 6 ч $(17,24,25)$. Ранее считалось, что секреция ЛГ подчиняется циркадному ритму, начинающемуся с момента выключения света («точки заката»), и продолжается 8-10 ч («открытый период») (2528). Эту концепцию пересмотрели в 2007 году, когда N. Nakao с соавт. (29) показали, что у перепелок в близких к овуляции фолликулах имеются «часовые гены», связанные с экспрессией стероидогенного острого регуляторного протеина StAR, который критически важен для транспорта холестерина к внутренней мембране митохондрий и служит лимитирующим фактором для начала синтеза прогестерона $\left(\mathrm{P}_{4}\right)(30)$. То есть экспрессия StAR в фолликуле $\mathrm{F}_{1}$ изменяется с периодичностью 24 ч вместе с экспрессией часового гена Per2. Кроме того, в гене StAR были обнаружены участки для связывания с генами CLOCK/BMAL1, которые инициируют транскрипцию. Следовательно, время овуляции фолликулов в яичнике птиц контролируется циркадным ритмом, регулируемым часовыми генами. Последние усиливают генетическую экспрессию StAR в фолликуле $\mathrm{F}_{1}$ и обеспечивают увеличение концентрации прогестерона в плазме крови, достаточное для запуска предовуляторного выброса ЛГ (31). Кроме того, ЛГ участвует в регуляции активности гена $C L O C K / B M A L 1$ и стимулирует усиление экспрессии гена StAR, что увеличивает секрецию прогестерона и еще сильнее ускоряет процесс предовуляторного выброса ЛГ. Синтез прогестерона - ключевое событие, определяющее время секреции ЛГ и, как следствие, продолжительность открытого периода благодаря положительной обратной регуляторной связи между этими двумя гормонами (32).

Основная функция выделения ЛГ - это запуск овуляции $(14,23)$, поэтому отсутствие пика концентрации гормона блокирует овуляцию у несушек (17). Кроме того, ЛГ участвует в процессе созревания фолликулов (33) и стероидогенезе в мелких и крупных фолликулах $(34,35)$. Показано, что инъекции экзогенного ЛГ стимулируют секрецию $\mathrm{P}_{4}$ созревшим фолликулом перед овуляцией и секрецию эстрадиола $\left(\mathrm{E}_{2}\right)$ фолликулом $\mathrm{F}_{3}(36)$. В гранулезных клетках фолликулов в иерархии (от 9 мм в диаметре) присутствуют рецепторы ЛГ (ЛГ-Р), и экспрессия мРНК ЛГ-Р усиливается по мере созревания фолликула $(37,38)$.

При режиме 16С:8T (16 ч свет, 8 ч темнота) начало повышения преовуляторной концентрации ЛГ в крови у кур приходится на время, примерно соответствующее «точке заката», тогда как у несушек, содержавшихся при режиме 8С:16Т, - на 3-4 ч позднее $(23,39)$. Промежуток между достижением пиковой концентрации ЛГ в крови и овуляцией обычно составляет около 5 ч и не зависит от яйценоскости, положения яйца в цикле кладки или режима освещения несушек (40-42).

Время формирования яйца в яйцеводе варьируется сильнее. Оно зависит от того, насколько интенсивно птица несется, и от положения яйца в цикле яйцекладки. Сообщалось, что время формирования яйца увеличивается примерно на 1 ч при содержании несушек в свето-темновых циклах длиной 27 ч и более (43). Общий интервал между достижением 
пиковой концентрации ЛГ в крови и снесением полностью сформированного яйца может варьировать от 29 до 31 ч (44).

Влияние режимов освещения на время яйцеклад к и. При обычной продолжительности (24 ч) свето-темновых циклов снесение яйца, а значит, и овуляция происходят в течение 8-часового «открытого периода» $(14,28,45,46)$. Наблюдения показали, что в стандартных свето-темновых циклах при однократном чередовании света (C) и темноты (T) (например, 16С:8T, 14С:10T) яйцекладка происходит в основном за световой период (47-49), а при режимах прерывистого освещения ассиметричного типа (например, 2С:4T:8C:10T, 1C:5T:3С:4T:3C:8T, 1C:4T:4C:1T:4C:10T) — в течение «субъективного дня» (период, который птица воспринимает как световой день) (50-53). В 28-часовых свето-темновых циклах (например, 12С:16Т) 84,5 \% яиц от суточного сбора куры несут в течение последних 9 ч темнового периода (48).

По данным M. Gumulka с соавт. (54), высокопродуктивные мясные куры кросса Arbor Acres с 168- до 448-суточного возраста при режиме 16С:8Т (фотопериод с $5^{00}$ до $21^{00}$ ) сносили первое яйцо в цикле яйцекладки примерно через 3,5 ч после включения света. С увеличением продолжительности ЦЯ первое яйцо откладывалось раньше, а ИЯ сокращался. При исследовании яичных кур высокой и низкой линии породы белый леггорн при режиме освещения 12С:12Т (фотопериод с $6^{00}$ до 1800) с 270до 360-суточного возраста первое яйцо в цикле из 3, 4, 7 и 10 яиц было снесено соответственно через 1 ч 35 мин и 1 ч 51 мин; 1 ч 25 мин и 56 мин; 1 ч 06 мин и 30 мин; 34 и 30 мин после включения света (55).

Установлено, что время снесения первого яйца зависит от продолжительности ЦЯ, если он состоит из 2-5 яиц: чем длинней цикл, тем раньше происходит снесение первого яйца после включения света. При большей продолжительности цикла эта закономерность нарушается (14).

При групповом содержании кур на фоне прерывистого освещения время начала яйцекладки зависит от длительности «субъективного дня» (56). Так, при его продолжительности 16, 15, 14 и 13 ч/сут (во всех группах начало «субъективного дня» в $2^{00}$ ) яйцекладка в стаде начиналась ночью: соответственно в $4^{00}, 3^{00}, 2^{00}$ и $1^{00}$.

Есть сведения о том, что снесение большей части яиц от суточного сбора происходит примерно через 5-6 ч после включения света (57), что соответствует среднему времени яйцекладки 13-14 ч после наступления темноты $(45,58)$. Аналогичные результаты были получены B.G. Roy c coавт. (18), которые сообщают, что при режиме 16C:8T (фотопериод с $6^{00}$ до $22^{00}$ ) среднее время яйцекладки составило $\sim 10^{59}$, то есть оно наступало спустя 5 ч после включения света (или через 13 ч после наступления темнового периода).

С возрастом кур среднее время яйцекладки увеличивается. Так, при одинаковом режиме освещения молодые (33 нед) куры яичных кроссов снесли 50 \% яиц от суточного сбора через 13 ч после выключения света, а несушки более старшего возраста (76 нед) - на 30-60 мин позже (59). Аналогичные результаты были получены на курах мясных кроссов: молодое стадо (34 нед) снесло большинство яиц между $7^{00}$ и $13^{00}$, в то время как старшее стадо (59 нед) - между $7^{00}$ и $15^{00}$ (57).

При содержании кур в условиях круглосуточного освещения или круглосуточной темноты (60), а также при прерывистом освещении симметричного типа с короткими циклами, например 3С:3Т и 4С:4T $(61,62)$, яйцекладка продолжалась на протяжении 24 ч в сутки. Однако при режиме 2С:10T:2С:10T основное количество яиц было снесено в первую 10- 
часовую темновую фазу, точнее в первый час этой фазы (63).

По утверждению P.Н. Patterson (58), у кур высокопродуктивных кроссов при 24-часовых свето-темновых циклах яйцекладка редко происходит в темноте. Как правило, при стандартных режимах освещения (например 14С:10Т) яйца сносятся между $7^{30}$ и $8^{15}$ и между $15^{30}$ и $16^{00}$ (64). По другим данным, наибольшая доля яиц откладывается между $10^{00}$ и $12^{00}(65), 10^{00}$ и $14^{00}(66)$ или в ранние утренние часы световой фазы при режимах 14С:10T и 17С:7Т (67). Известно также, что при многих нестандартных режимах освещения несушки сносят яйца и в темноте. Показано, что при режиме 14С:7Т куры откладывают много яиц сразу после выключения света, а при 14С:14Т - в темновую фазу (68).

P.D. Lewis c coaвт. (69) изучали время яйцекладки у гибридных кур, несущих яйца с коричневой и белой скорлупой, при продолжительности фотопериода 8, 10, 13 и 18 ч. Установлено, что среднее время яйцекладки у обоих кроссов увеличивается относительно «точки заката» приблизительно на 0,5 ч на каждый 1 ч удлинения фотопериода. Причем среднее время яйцекладки у коричневого кросса было на 1,2-1,4 ч меныше, чем у белого, при каждом режиме освещения. Похожие результаты получены в работе D. Backhouse (28). Увеличение продолжительности светового дня с 10 до 14 ч в 24-часовых свето-темновых циклах приводило к смещению среднего времени снесения яйца к «закату» на 0,5 ч на каждый 1 ч увеличения фотопериода, тогда как при продолжительности светового дня 14 и 16 ч оно было практически одинаковым. Время снесения стадом 50 \% яиц от суточного сбора также сдвигалось к «закату» на 0,5 ч на каждый дополнительный час фотопериода, причем этот показатель продолжал сдвигаться и после 14-часового светового дня. При длине светового дня меньше 12,25 ч число яиц, снесенных до «рассвета» (включения света), увеличивалось на 4,5 \% на каждый 1 ч уменьшения продолжительности фотопериода.

P.D. Lewis c coaвT. (70) изучали режимы освещения с дополнительными периодами тусклого света до и после обычного 8-часового фотопериода в сравнении с 16-часовым фотопериодом. При 8-часовом фотопериоде и дополнительном тусклом свете время снесения яиц было одинаковым, однако при 16-часовом фотопериоде оно снижалось на 3 ч.

E. Tůmová c coaвт. (71) установили, что в условиях напольного содержания время снесения основного количества яиц сдвигается ближе к середине дня (на 1000) по сравнению с таковым для клеточной системы содержания (где большую часть яиц птица сносила около $6^{00}$ ) при одинаковом режиме освещения.

В наших исследованиях (56) при продолжительности «субъективного дня» $16,15,14$ и 13 ч/сут и одновременном включении света в $2^{00}$ ночи на фоне прерывистого освещения (1C:6T:4C:2T:3C:8T, 1C:5T:4C:2T:3C:9T, $1 \mathrm{C}: 4 \mathrm{~T}: 4 \mathrm{C}: 2 \mathrm{~T}: 3 \mathrm{C}: 10 \mathrm{~T}$ и $1 \mathrm{C}: 3 \mathrm{~T}: 4 \mathrm{C}: 2 \mathrm{~T}: 3 \mathrm{C}: 11 \mathrm{~T})$ среднее время снесения яиц составило $8^{40}, 7^{22}, 5^{22}$ и $5^{16}$ (или через 14 ч 40 мин, 14 ч 22 мин, 13 ч 22 мин и 14 ч 16 мин после наступления самого большого темнового периода «субъективной ночи», то есть «точки заката»).

Роль времени включения и выключения света («восхода» и «заката») в ритме яйцекладки изучалась во многих работах. М. Naito с соавт. (72) отмечают, что «восход» и «закат» оказывают примерно одинаковое влияние на настройку времени яйцекладки. По мнению многих авторов (26, 44, 73-75), время «заката» важнее, независимо от продолжительности светового периода. Так, при содержании кур-несушек породы белый леггорн при постоянном освещении 16С:8T или 20С:4T смещение времени выключения света оказывало более сильное (ответ - 74 \%) влияние на 
время снесения яиц, чем смещение времени включения света (ответ - 3538 \%) (73). При одновременном смещении времени включения и выключения света ответ времени яйцекладки составлял $94 \%$. Время яйцекладки смещалось в том же направлении, в котором смещали темновую фазу.

При более продолжительном темновом периоде среднее время яйцекладки смещалось назад, считая от «точки заката»: при режиме 20С:4T оно составляло 919-935, при $16 \mathrm{C}: 8 \mathrm{~T}-10^{30}-10^{59}$. Эти данные свидетельствуют о том, что при 24-часовых свето-темновых циклах на время яйцекладки оказывает влияние не только время «рассвета» и «заката», но также длина и положение темновой фазы. Следует отметить, что если время «заката» сдвинуть вперед или назад при постоянном времени включения света, то сдвиг во времени яйцекладки не будет равен сдвигу времени «заката» (76). В исследовании S.C. Wilson с соавт. (23) было показано, что при переводе кур со светового режима 16С:8T («рассвет» в 2400) на 20С:4T («рассвет» в $20^{00}$ ) сдвиг назад среднего времени яйцекладки составил всего 30 мин (500 против $\left.5^{30}\right)$. Однако при той же схеме 20С:4T («закат» в $20^{00}$ ), но со сдвигом вперед времени «заката» на те же 4 ч среднее время яйцекладки составило $8^{38}$, то есть сдвигалось вперед на 3 ч 8 мин.

По мнению некоторых авторов $(73,77)$, среднее время яйцекладки в условиях стандартных свето-темновых циклов определяется прежде всего временем «заката», хотя «рассвет» также оказывает определенное влияние. Можно предположить, что время снесения яиц у кур обусловлено сложным взаимодействием между этими двумя сигналами. По сообщению R.J. Etches (68), при стандартном цикле 14C:10Т среднее время яйцекладки составляет примерно 15 ч после «заката». Однако продление темновой фазы до 18 ч или сокращение до 6 ч приводили к сдвигу среднего времени снесения яиц на 4 ч вперед или на 3 ч назад.

B опыте E. Tůmová c соавт. (78) обнаружено, что при включении света в $3^{00}$ основное количество яиц куры сносят в $6^{00}$, а затем количество откладываемых яиц равномерно снижается в течение остального дня. Включение света в $6^{00}$ при напольном содержании несушек приводило к такому же равномерному снижению процента сносимых яиц. Эти результаты свидетельствуют о том, что равномерность снесения яиц в течение дня зависит от времени включения света, а также, по всей вероятности, от системы содержания несушек.

B.M. Bhatti c соавт. (44) после анализа результатов многочисленных исследований с продолжительностью свето-темновых циклов от 24 до 30 ч и собственно темновой фазы от 5 до 23 ч предложили уравнение, которое позволяет оценить среднее время снесения (СВC, ч) яиц от «точки заката» при этих циклах:

$$
\mathrm{CBC}=16,619-2(Ц-24)-0,161 Ц+0,268 \mathrm{~T},
$$

где Ц - длительность цикла, ч; Т - продолжительность темновой фазы, ч. Отмечают, что при циклах длиннее 24 ч изменение продолжительности темновой фазы оказывает более выраженный эффект на время снесения яиц, чем при 24-часовых циклах (79).

Однако наши расчеты (табл.), проведенные с использованием этого уравнения, показали, что увеличение продолжительности цикла на 1 ч при одинаковой длительности фотопериода приводит к сокращению среднего времени снесения яиц на 1,89-1,90 ч. Увеличение же продолжительности темнового периода на 1 ч внутри каждого цикла сдвигает СВС яиц на 0,26-0,27 ч в сторону «заката». 
Среднее время снесения (СВС, ч) яиц курами (Gallus gallus domesticus) при разной продолжительности свето-темновых циклов

\begin{tabular}{|c|c|c|c|c|}
\hline $\begin{array}{l}\text { Продолжи- } \\
\text { тельность } \\
\text { цикла, ч }\end{array}$ & $\begin{array}{l}\text { Режим } \\
\text { освещения }\end{array}$ & $\begin{array}{l}\text { СВС яиц от } \\
\text { точки «заката» }\end{array}$ & \begin{tabular}{|l|} 
Сокращение СВС при \\
увеличении цикла на 1 ч \\
за счет темнового периода
\end{tabular} & $\begin{array}{l}\text { Сдвиг СВС к точке «заката» } \\
\text { при увеличении темновой } \\
\text { фазы на } 1 \text { ч внутри цикла }\end{array}$ \\
\hline \multirow{4}{*}{24} & $16 \mathrm{C}: 8 \mathrm{~T}$ & 14,90 & & \\
\hline & $15 \mathrm{C}: 9 \mathrm{~T}$ & 15,17 & & 0,27 \\
\hline & $14 \mathrm{C}: 10 \mathrm{~T}$ & 15,44 & & 0,27 \\
\hline & $13 \mathrm{C}: 11 \mathrm{~T}$ & 15,70 & & 0,26 \\
\hline \multirow[t]{4}{*}{25} & 16C:9T & 13,00 & 1,90 & \\
\hline & $15 \mathrm{C}: 10 \mathrm{~T}$ & 13,27 & 1,90 & 0,27 \\
\hline & $14 \mathrm{C}: 11 \mathrm{~T}$ & 13,54 & 1,90 & 0,27 \\
\hline & $13 \mathrm{C}: 12 \mathrm{~T}$ & 13,81 & 1,89 & 0,27 \\
\hline \multirow[t]{4}{*}{26} & $16 \mathrm{C}: 10 \mathrm{~T}$ & 11,11 & 1,89 & \\
\hline & $15 \mathrm{C}: 11 \mathrm{~T}$ & 11,38 & 1,89 & 0,27 \\
\hline & $14 \mathrm{C}: 12 \mathrm{~T}$ & 11,65 & 1,89 & 0,27 \\
\hline & $13 \mathrm{C}: 13 \mathrm{~T}$ & 11,92 & 1,89 & 0,27 \\
\hline \multirow[t]{4}{*}{27} & $16 \mathrm{C}: 11 \mathrm{~T}$ & 9,22 & 1,89 & \\
\hline & $15 \mathrm{C}: 12 \mathrm{~T}$ & 9,49 & 1,89 & 0,27 \\
\hline & $14 \mathrm{C}: 13 \mathrm{~T}$ & 9,76 & 1,89 & 0,27 \\
\hline & $13 \mathrm{C}: 14 \mathrm{~T}$ & 10,02 & 1,90 & 0,26 \\
\hline \multirow[t]{4}{*}{28} & $16 \mathrm{C}: 12 \mathrm{~T}$ & 7,33 & 1,89 & - \\
\hline & $15 \mathrm{C}: 13 \mathrm{~T}$ & 7,59 & 1,90 & 0,27 \\
\hline & $14 \mathrm{C}: 14 \mathrm{~T}$ & 7,86 & 1,90 & 0,27 \\
\hline & $13 \mathrm{C}: 15 \mathrm{~T}$ & 8,13 & 1,89 & 0,27 \\
\hline \multirow[t]{4}{*}{29} & $16 \mathrm{C}: 13 \mathrm{~T}$ & 5,43 & 1,90 & \\
\hline & $15 \mathrm{C}: 14 \mathrm{~T}$ & 5,70 & 1,89 & 0,27 \\
\hline & $14 \mathrm{C}: 15 \mathrm{~T}$ & 5,97 & 1,89 & 0,27 \\
\hline & $13 \mathrm{C}: 16 \mathrm{~T}$ & 6,24 & 1,73 & 0,27 \\
\hline \multirow[t]{4}{*}{30} & $16 \mathrm{C}: 14 \mathrm{~T}$ & 3,54 & 1,89 & \\
\hline & $15 \mathrm{C}: 15 \mathrm{~T}$ & 3,81 & 1,89 & 0,27 \\
\hline & $14 \mathrm{C}: 16 \mathrm{~T}$ & 4,08 & 1,89 & 0,27 \\
\hline & $13 \mathrm{C}: 17 \mathrm{~T}$ & 4,35 & 1,89 & 0,27 \\
\hline
\end{tabular}

П р и м е ч а н и е. С - свет, Т - темнота. Циклы сравнивали при одинаковой продолжительности фотопериода.

Старение репродуктивной системы кур выражается в удлинении интервалов между овуляциями и снесениями яиц внутри одного цикла яйцекладки, а также в бо́льшем числе пауз между ЦЯ, то есть суток, когда курица не несется вообще. По предположению G.C. Emmans с соавт. (80), у кур с возрастом увеличивается продолжительность образования яйца, что приводит к уменышению частоты овуляций и снесений яиц. Снижение частоты овуляций и сокращения продолжительности яйцекладок может быть также связано с изменениями циркадного ритма, процесса созревания фолликулов или с обоими этими факторами. С возрастом у кур не только сужается амплитуда циркадного ритма, но и меняется ответ некоторых циркадных процессов в организме на световую стимуляцию. В целом, у более старых несушек продолжительность цикла яйцекладки всегда меньше, чем у молодых (81).

Задержки в снесении яиц могут происходить из-за стрессов, вызванных условиями содержания (особенно при альтернативных системах содержания), пересадками, контактом с незнакомыми особями, удалением привычных для несушек гнезд для откладывания яиц $(82,83)$. В своем исследовании A.D. Mills с соавт. (84) показали, что беспокойство увеличивает интервалы между снесениями яиц у несушек.

Установлено, что существенное влияние на суточный ритм яйцекладки оказывает продолжительность освещения в светочувствительную фазу (она начинается спустя 11 ч после первого включения света и длится в течение 5 ч) (53). Так, при освещении в светочувствительную фазу в течение 1,3 и 5 ч на фоне режимов 1С:5T:5C:4T:1C:8T, 1C:5T:3С:4T:3С:8Т и $1 \mathrm{C}: 5 \mathrm{~T}: 1 \mathrm{C}: 4 \mathrm{~T}: 5 \mathrm{C}: 8 \mathrm{~T}$ яйцекладка начиналась через 2 ч после первого включения света. При этом до $13^{00}$ было снесено соответственно 90,9; 85,7 и 
$80,5 \%$ яиц от суточного сбора, масса яиц составила 61,9; 61,2 и 60,1 г, а упругая деформация скорлупы - 22,4; 22,6 и 22,5 мкм.

Влияние времени яйцекладки на качество яиц и продуктивность кур. В многочисленных исследованиях установлено, что время яйцекладки влияет на качество яиц и продуктивность птицы (8587). Так, масса яиц, снесенных рано утром, была выше, чем снесенных в течение дня $(82,88-92)$. Время снесения яйца играет важную роль в формировании качества скорлупы, поскольку масса отложенной скорлупы линейно зависит от времени, проведенного яйцом в матке яйцевода $(64,93)$.

Известно, что время снесения яйца оказывает значительное влияние на массу скорлупы: она выше у яиц, снесенных до $7^{45}$, чем у яиц, снесенных между $7^{45}$ и $11^{45}$ (94). Затем масса скорлупы достоверно возрастает до времени снесения $12^{45}$ и остается высокой в течение всего остатка светового дня, исключая период между $14^{45}$ и $16^{45}$. Z. Pavlovski c coавт. (88) показали, что яйца, снесенные в более поздний период дня, имели лучшие характеристики качества скорлупы, чем утром. По сообщению Е. Tůmová c соавт. (95), масса скорлупы снижалась в течение светового дня, причем особенно сильно у кросса Иса Браун (ISA-Brown, «Hendrix Genetics», Нидерланды): у этого генотипа средняя масса скорлупы яйца составляла 6,38 г в $6^{00}$ и 6,23 г - в $14^{00}$. В других исследованиях $(78,96)$ масса скорлупы была максимальной в середине светового дня (в $\left.14^{00}\right)$. Исходя из этого, авторы предположили, что масса скорлупы имеет тенденцию к повышению к последнему яйцу в кладке.

Время яйцекладки влияет также на толщину скорлупы. Есть мнение (97), что лучшее качество скорлупы яиц, снесенных в середине дня, связано с ее большей толщиной. Это предположение согласуется с данными о том, что толщина скорлупы у утренних яиц меньше, чем у полуденных $(78,96)$. Вместе с тем сообщалось и о достоверно большей толщине скорлупы в утренние часы $\left(6^{00}\right)$ с последующим снижением этого показателя, что, возможно, связано с генотипом несушек, использованных в разных опытах (71).

C. Hrnčár c соавт. (98) изучали влияние времени яйцекладки на показатели качества яиц на курах-несушках трех пород (коричневый леггорн, оравка и брама - Brown Leghorn, Oravka, Brahma) с 20- до 64-недельного возраста. Птицу содержали на глубокой подстилке. Яйца собирали в $6^{00}$, $10^{00}$ и $14^{00}$ - в начале, середине и конце продуктивного периода. У кур породы брама максимальную массу яйца $\left(59,96\right.$ г) отмечалась в $6^{00}$, а относительная масса $(10,53 \%)$, прочность $(29,88$ н/см²) и толщина скорлупы $(381,88$ мкм) были выше $(\mathrm{p} \leq 0,05)$ в 1400 . У коричневых леггорнов время яйцекладки не оказало существенного влияния на массу яйца, относительную массу и индекс желтка. Наибольшую $(\mathrm{p} \leq 0,05)$ толщину скорлупы (398,84 мкм) отмечали в $6^{00}$, а максимальные значения индекса белка $(7,39 \%)$ и числа единиц Хау $(72,21)$ - в 1400 . У кур породы оравка время яйцекладки существенно не повлияло на массу яйца, относительную массу белка, желтка и скорлупы, индекс белка и желтка, единицы Хау. При этом более высокое значение толщины скорлупы $(381,88$ мкм, p $\leq 0,05)$ приходилось на $14^{00}$. В другом опыте (92) при изучении влияния времени яйцекладки на качество яиц масса яиц, собранных в $10^{00}$ и $14^{00}$, составила 65,25 и 63,94 г; абсолютная и относительная масса скорлупы - 7,78 и 7,64 г; 11,93 и 11,98 \%; белка - 40,91 и 39,94 г; 62,65 и 62,42 \%; желтка 16,56 и 16,35 г; 25,42 и 25,60 \%; индекс формы яйца - 76,72 и 76,70 \%; единицы Хау - 76,60 и 76,70; толщина скорлупы - 0,51 и 0,54 мм; цвет скорлупы - 12,18 и 12,16 балла. 
E. Tůmová c coaвт. (99) сообщают о значительном влиянии времени снесения яйца на накопление в скорлупе минеральных веществ. Так, в яйцах, снесенных в $7^{30}$, содержание кальция было максимальным - 352 г/кг, тогда как в $15^{30}$ оно составило 342 г/кг. Содержание фосфора и магния в скорлупе повышалось со сдвигом времени снесения яиц на более поздние сроки: в $7^{30}$ эти показатели составили соответственно 1,20 и 3,56 г/кг, а в $15^{30}-1,43$ и 3,88 г/кг. Е. Kebreab с соавт. (100) предполагают, что более высокое содержание кальция в скорлупе утренних яиц связано с усилением депонирования кальция в медуллярной кости в темновую фазу суток.

По данным ряда авторов $(90,92)$, время яйцекладки влияет на цвет коричневой скорлупы. Так, темноокрашенные яйца куры сносят утром, а более светлые - позднее в течение светового дня (после $10^{00}$ ). Интенсивность коричневого цвета уменьшалась с возрастом стада, а положение яйца в кладке относительно мало влияло на коричневый цвет яичной скорлупы (90). Помимо того, что коричневый цвет яичной скорлупы играет определенную роль в потребительских предпочтениях, присутствие пигмента, обусловливающего такое окрашивание, положительно коррелирует с прочностью и толщиной скорлупы, а также с выводимостью яиц (101104). Японские ученые показали, что коричневый пигмент обладает фотодинамически независимыми антибактериальными свойствами в отношении некоторых грамположительных микроорганизмов, таких как Staphylococcus aureus и Bacillus cereus (105).

Установлено, что время яйцекладки влияет на накопление в яйце холестерина. Так, в утренних яйцах его на 22,8 \% меньше, чем в дневных, - соответственно 12,53 против 16,23 мг/г желтка. Кроме того, в утренних яйцах значительно ниже содержание общего холестерина в желтке (176,63 мг/яйцо), чем в дневных $(221,14$ мг/яйцо) $(93,106)$.

K. Lillpers (45) сообщает о том, что куры, характеризующиеся ранней по времени яйцекладкой, более продуктивны по сравнению с теми, которые несутся в более позднее время. По его данным, наследуемость $\left(\mathrm{h}^{2}\right)$ времени яйцекладки находится в диапазоне от 0,38 до 0,78. Генетические и фенотипические связи между этим и классическими признаками (яйценоскость, масса яиц и т.д.) в основном положительные. В более поздних исследованиях $(11,107)$ установлена положительная связь между продолжительностью цикла яйцекладки и яйценоскостью: коэффициент корреляции $(r)$ между этими показателями составляет 0,54. То есть генетически обусловленное увеличение средней продолжительности цикла яйцекладки приведет к значительному повышению общей яйценоскости кур.

Таким образом, освещение - один из основных экзогенных факторов, оказывающих значительное влияние на время яйцекладки у кур. Среднее время снесения яиц непосредственно связано со сроком овуляции, которая происходит спустя 5 ч после достижения пиковой концентрации лютеинизирующего гормона в крови и не зависит от порядкового номера яйца в цикле кладки и яйценоскости несушек. При отсутствии пика концентрации этого гормона овуляция блокируется. При стандартных 24-часовых свето-темновых циклах на фоне постоянного освещении (например, 16С:8Т, 14С:10T) снесение яиц происходит в основном за световой период, а на фоне режимов прерывистого освещения ассиметричного типа (например, 2С:4T:8С:10T, 1С:4T:4С:2Т:3С:10T) - в течение «субъективного дня». В условиях круглосуточного фотопериода или постоянной темноты, а также прерывистого освещения симметричного типа (например, 3C:3Т, 4C:4T), куры несутся на протяжении 24 ч в сутки. Чем меньше продолжительность светового или «субъективного» дня, тем раньше начи- 
нается яйцекладка и меньше среднее время снесения яиц по стаду. Снесение основного количества яиц от суточного сбора происходит в течение 56 ч после начала светового или «субъективного» дня, при этом среднее время яйцекладки находится в пределах 13-15 ч после наступления темноты. При 24-часовых свето-темновых циклах среднее время яйцекладки становится результатом сложного взаимодействия сроков включения и выключения света - «рассвета» и «заката» при превалирующем влиянии «точки заката». В условиях однократного чередование света и темноты в циклах 24-30 ч увеличение продолжительности цикла на 1 ч при одинаковой длительности фотопериода приводит к сокращению среднего времени снесения яиц на 1,89-1,90 ч. Повышение же продолжительности темнового периода на 1 ч внутри каждого цикла сдвигает среднее время яйцекладки на 0,26-0,27 ч в сторону «точки заката». Чем меныше среднее время снесения яиц, тем длинней цикл яйцекладки и выше продуктивность кур. Наследуемость времени яйцекладки составляет 0,38-0,78, коэффициент корреляции между продолжительностью цикла яйцекладки и яйценоскостью - 0,54. Данные по влиянию времени яйцекладки на качество яиц противоречивы. Одни авторы отмечают лучшие показатели (масса, толщина и прочность скорлупы) у яиц, снесенных утром, другие, наоборот, в середине дня. У утренних яиц интенсивнее окраска скорлупы и выше содержание в скорлупе кальция, тога как фосфора, магния и холестерина в желтке - ниже (на 22,8 \%), чем в яйцах, снесенных после полудня (после $12^{00}$ ). Эти факты указывают на целесообразность и перспективность включения показателей среднего времени яйцекладки (ВЯ) и длительности ее цикла (ЦЯ) в программу селекции на улучшение яичных и мясных кроссов. Кроме того, оптимизация времени яйцекладки позволит рационализировать сбор яиц и улучшить их качество на птицефабриках. Следует отметить, что изучение влияния освещения на время яйцекладки и качество яиц проводилось в основном при режиме постоянного освещения. Необходимы углубленные исследования в условиях прерывистого светового дня как при индивидуальном (с учетом порядкового номера яиц в цикле), так и при групповом содержании кур.

\section{Л И Т Е Р А Т У Р А}

1. Lukić M., Pavlovski Z., Škrbić Z. Adequate calcium nutrition and quality of egg shell and bones in layers: innovative approach. Biotechnology in Animal Husbandry, 2011, 27(3): 485-497 (doi: 10.2298/BAH1103485L).

2. Штелле А.Л. Образование биологически полноценных яиц и продуктивность кур яичных кроссов. Птица и птицепродукты, 2011, 6: 19-23.

3. Nys Y., Guyot N. Egg formation and chemistry. In: Improving the safety and quality of eggs and egg products. Food Science, Technology and Nutrition /Y. Nys, M. Bain, F. Van Immerseel (eds.). Woodhead Publishing Limited, 2011: 83-132 (doi: 10.1533/9780857093912.2.83).

4. Сидоренко Л.И., Щербатов В.И. Биология кур. Краснодар, 2016: 244.

5. Johnson A.L., Woods D.C. Ovarian dynamics and follicle development. In: Reproductive biology and phylogeny of birds /B.G.M. Jamieson (ed.). Science Publishers, Enfield, USA, 2007, 6A: 243-277.

6. Rangel P.L., Gutierrez C.G. Reproduction in hens: is testosterone necessary for the ovulatory process? General and Comparative Endocrinology, 2014, 203: 250-261 (doi: 10.1016/j.ygcen.2014.03.040).

7. Johnson A.L. Regulation of follicle differentiation by gonadotropins and growth factor. Poultry Science, 1993, 72(5): 867-873 (doi: 10.3382/ps.0720867).

8. Johnson A.L. The avian ovarian hierarchy: a balance between follicle differentiation and atresia. Avian and Poultry Biology Reviews, 1996, 7(2-3): 99-110.

9. Sauveur B., de Reviers M. Qualite d'œufs. In: Reproduction des volailles et production d'oufs. INRA, Paris, 1988: 377-436.

10. Sheldon B.L., Yoo B.H., Podger R.N. Increasing egg yield under normal light cycles by selecting for short interval between eggs under continuous light. Annales Agriculturae Fenniae, 1984, 
23(4): 216-225.

11. Bednarczyk M., Kiecłzewski K., Szwaczkowski, T. Genetic parameters of the traditional selection traits and some clutch traits in a commercial line of laying hens. Archiv für Geflügelkunde, 2000, 64(3): 129-133.

12. Chen C.F., Tixier-Boichard M. Correlated responses to long-term selection for clutch length in dwarf brown-egg layers carrying or not carrying the naked neck gene. Poultry Science, 2003, 82(5): 709-720 (doi: 10.1093/ps/82.5.709).

13. Bain M.M., Nys Y., Dunn I.C. Increasing persistency in lay and stabilising egg quality in longer laying cycles. What are the challenges? British Poultry Science, 2016, 57(3): 330-338 (doi: 10.1080/00071668.2016.1161727).

14. Etches R.J. Reproduction in poultry. CAB International, Wallingford, UK, 1996.

15. Icken W., Cavero D., Schmutz M., Thurner S., Wendl G., Preisinger R. Analysis of the time interval within laying sequences in a transponder nest. World's Poultry Science Journal, 2008, 64: 231-234.

16. Croze F. Etches R.J. The physiological significance of androgen-induced ovulation in the hen. Journal of Endocrinology, 1980, 84(1): 163-171 (doi: 10.1677/joe.0.0840163).

17. Rangel P.L., Sharp P.J., Gutierrez C.G. Testosterone antagonist (flutamide) blocks ovulation and preovulatory surges of progesterone, luteinizing hormone and oestradiol in laying hens. $R e-$ production, 2006, 131(6): 1109-1114 (doi: 10.1530/rep.1.01067).

18. Roy B.G., Kataria M.C., Roy U. Study of oviposition pattern and clutch traits in a White leghorn (WL) layer population. IOSR Journal of Agriculture and Veterinary Science, 2014, 7(1): 5967 (doi: 10.9790/2380-07115967).

19. Backhouse D., Gous R.M. The effect of feeding time on shell quality and oviposition time in broiler breeders. British Poultry Science, 2005, 46(2): 255-259 (doi: 10.1080/00071660500066258).

20. Backhouse D., Gous R.M. Responses of adult broiler breeders to feeding time. World's Poultry Science Journal, 2006, 62(2): 269-281 (doi: 10.1079/WPS200596).

21. Lewis Dr P.D., Ciacciariello M., Ciccone N.A., Sharp P.J., Gous R.M. Lighting regimens and plasma LH and FSH in broiler breeders. British Poultry Science, 2005, 46(3): 349-353 (doi: 10.1080/00071660500098509).

22. Tůmová E., Gous R.M. Interaction between oviposition time, age, and environmental temperature and egg quality traits in laying hens and broiler breeders. Czech Journal of Animal Science, 2012, 57(12): 541-549 (doi: 10.17221/6411-CJAS).

23. Wilson S.C., Cunningham F.J. Endocrine control of ovulation cycle. In: Reproductive biology of poultry /F.J. Cunningham, P.E. Lake, D. Hewitt (eds.). British Poultry Science Ltd., Edinburgh, UK, 1984: 29-51.

24. Johnson A.L., van Tienhoven A. Hypothalamo-hypophyseal sensitivity to hormones in the hen. I. Plasma concentrations of $\mathrm{LH}$, progesterone and testosterone in response to central injections of progesterone and R5020. Biology of Reproduction, 1980, 23(5): 910-917 (doi: 10.1095/biolreprod23.5.910).

25. Wilson S.C., Jennings R.C., Cunningham F.J. An investigation of diurnal and cyclic changes in the secretion of luteinizing hormone in the domestic hen. Journal of Endocrinology, 1983, 98(1): 137-145 (doi: 10.1677/joe.0.0980137).

26. Morris T.R. The effects of ahemeral light and dark cycles on egg production in the fowl. Poultry Science, 1973, 52(2): 423-445 (doi: 10.3382/ps.0520423).

27. Johnson P.A., van Tienhoven A. Investigations of the significance of the crepuscular LH peak in the ovulatory cycle of the hen (Gallus domesticus). Journal of Endocrinology, 1984, 100(3): 307-313 (doi: 10.1677/joe.0.1000307).

28. Backhouse D. The effect of photoperiod and feeding time on broiler breeder eggshell quality and oviposition time. University of KwaZulu-Natal, Pietermaritzburg, 2004: 74.

29. Nakao N., Yasuo S., Nishimura A., Yamamura T., Watanabe T., Anraku T., Okano T., Fukada Y., Sharp P.J., Ebihara S., Yoshimura T. Circadian clock gene regulation of steroidogenic acute regulatory protein gene expression in preovulatory ovarian follicles. Endocrinology, 2007, 148(7): 3031-3038 (doi: 10.1210/en.2007-0044).

30. Stocco D.M. StAR protein and the regulation of steroid hormone biosynthesis. Annual Review of Physiology, 2001, 63: 193-213 (doi: 10.1146/annurev.physiol.63.1.193).

31. Johnson A.L., Solovieva E.V., Bridgham J.T. Relationship between steroidogenic acute regulatory protein expression and progesterone production in hen granulosa cells during follicle development. Biology of Reproduction, 2002, 67(4): 1313-1320 (doi: 10.1095/biolreprod67.4.1313).

32. Wilson S.C., Sharp P.J. Effects of androgens, oestrogens and deoxycorticosterone acetate on plasma concentrations of luteinizing hormone in laying hens. Journal of Endocrinology, 1976, 69(1): 93-102 (doi: 10.1677/joe.0.0690093).

33. Cunningham F.J., Wilson S.C., Knight P.G., Gladwell R.T. Chicken ovulation cycle. Journal of Experimental Zoology, 1984, 232(3): 485-494 (doi: 10.1002/jez.1402320315).

34. Robinson F.E., Etches R.J. Ovarian steroidogenesis during follicular maturation in the domestic fowl (Gallus domesticus). Biology of Reproduction, 1986, 35(5): 1096-1105 (doi: 10.1095/biolreprod35.5.1096). 
35. Robinson F.E., Etches R.J., Anderson-Langmuir C.E., Burke W.H., Cheng K.W., Cunningham F.J., Ishii S., Sharp P.J., Talbot R.T. Steroidogenic relationships of gonadotrophin hormones in the ovary of the hen (Gallus domesticus). General and Comparative Endocrinology, 1988, 69(3): 455-466 (doi: 10.1016/0016-6480(88)90038-X).

36. Imai K., Nalbandov A.V. Plasma and follicular steroid levels of laying hens after the administration of gonadotropins. Biology of Reproduction, 1978, 19(4): 779-784 (doi: 10.1095/biolreprod19.4.779).

37. Johnson A.L., Bridgham J.T., Wagner B. Characterization of a chicken luteinizing hormone receptor (cLH-R) complementary deoxyribonucleic acid, and expression of cLH-R messenger ribonucleic acid in the ovary. Biology of Reproduction, 1996, 55(2): 304-309 (doi: 10.1095/biolreprod55.2.304).

38. Yamamura N., Takeishi M., Goto H., Tagami M., Mizutani T., Miyamoto K., Doi O., Kamiyoshi M. Expression of messenger RNA for gonadotropin receptor in the granulosa layer during the ovulatory cycle of hens. Comparative Biochemistry and Physiology Part A: Molecular \& integrative physiology, 2001, 129(2-3): 327-337 (doi: 10.1016/S1095-6433(00)00350-0).

39. Wilson S.C., Cunningham F.J. Effect of photoperiod on the concentrations of corticosterone and luteinizing hormone in the plasma of the domestic hen. Journal of Endocrinology, 1981, 91(1): 135-143 (doi: 10.1677/joe.0.0910135).

40. Etches R.J. Maturation of ovarian follicles. In: Reproductive biology of poultry /F.J. Cunningham, P.E. Lake, D. Hewitt (eds.). British Poultry Science Ltd., Edinburgh, UK, 1984: 51-73.

41. Gow C.B., Sharp P.J., Carter N.B., Scaramuzzi R.J., Sheldon B.L., Yoo B.H., Talbot R.T. Effects of selection for reduced oviposition interval on plasma concentrations of luteinizing hormone during the ovulatory cycle in hens on a 24-hr lighting cycle. British Poultry Science, 1985, 26(4): 441-451 (doi: 10.1080/00071668508416834).

42. Morris T.R., Melek O., Cunningham F.J. Luteinizing hormone concentrations in the plasma of laying hens exposed to a 27-hr cycle of light and darkness. Journal of Reproduction and Fertility, 1975, 42(2): 381-384 (doi: 10.1530/jrf.0.0420381).

43. Melek O., Morris T.R., Jennings R.C. The time factor in egg formation for hens exposed to ahemeral light-dark cycles. British Poultry Science, 1973, 14(5): 493-498 (doi: 10.1080/00071667308416056).

44. Bhatti B.M., Morris T.R. Model for the prediction of mean time of oviposition for hens kept in different light and dark cycles. British Poultry Science, 1988, 29(2): 205-213 (doi: $10.1080 / 00071668808417045)$.

45. Lillpers K. Genetic variation in the time of oviposition in the laying hen. British Poultry Science, 1991, 32(2): 303-312 (doi: 10.1080/00071669108417354).

46. Etches R.J. Physiology of reproduction: the female. In: Poultry production /P. Hunton (ed.). Elsevier, Amsterdam, the Netherlands, 1995: 221-241.

47. Cain J.R., Wilson W.O. The influence of specific environmental parameters on the circadian rhythm of chickens. Poultry Science, 1974, 53(4): 1438-1447 (doi: 10.3382/ps.0531438).

48. Noddegaard F. Oviposition patterns and plasma melatonin rhythms in response to manipulations of the light:dark cycle. British Poultry Science, 1998, 39(5): 653-661 (doi: 10.1080/00071669888539).

49. Кирдяшкина Г.А., Мальцев А.Б., Кавтарашвили А.Ш. Прерывистое освещение и время осеменения племенных кур яичных кроссов. Мат. Х Украинской конференции по птицеводству с международным участием «Актуальные проблемы современного птицеводства». Харьков, 2009: 222-225.

50. Lewis P.D., Perry G.C. Response of laying hens to asymmetrical interrupted lighting regimens: physiological aspects. British Poultry Science, 1990, 31(1): 45-52 (doi: 10.1080/00071669008417229).

51. Naito M., Ueno T., Komiyama T. The effect of intermittent lighting on the time of oviposition in the domestic fowl. Japanese Poultry Science, 1982, 19(4): 234-237 (doi: 10.2141/jpsa.19.234).

52. Кавтарашвили А.Ш. Его величество свет - основополагающий фактор в яичном птицеводстве. Птица и птицепродукты, 2007, 5: 45-47.

53. Кавтарашвили А.Ш., Марчев С.В., Риджал С.П. Влияние прерывистого освещения кур на суточный ритм яйцекладки и показатели продуктивности. В кн.: Сборник научных трудов ВНИТИП. Сергиев Посад, 2002, т. 77: 21-25.

54. Gumulka M., Kapkowska E., Maj D. Laying pattern parameters in broiler breeder hens and intrasequence changes in egg composition. Czech Journal of Animal Science, 2010, 55(10): 428435 (doi: 10.17221/1698-CJAS).

55. Miyoshi S., Inoue K., Minh Luc K., Kuchida K., Mitsumoto T. Intra-clutch changes in egg composition and shell quality in laying hens. Japanese Poultry Science, 1997, 34(4): 273-281 (doi: $10.2141 /$ jpsa.34.273).

56. Кавтарашвили А.Ш., Новоторов Е.Н., Гусев В.А., Присяжная Л.М. Суточный ритм яйцекладки и качество яиц при прерывистом освещении. Птица и птицепродукты, 2019, 3 : 38-41.

57. Zakaria A.H., Plumstead P.W., Romero-Sanchez H., Leksrisompong N., Osborne J., Braket J. Oviposition pattern, egg weight, fertility, and hatchability of young and old broiler breeders. Poultry Science, 2005, 84(9): 1505-1509 (doi: 10.1093/ps/84.9.1505).

58. Patterson P.H. The relationship of oviposition time and egg characteristics to the daily light:dark 
cycle. The Journal of Applied Poultry Research, 1997, 6(4): 381-390 (doi: 10.1093/japr/6.4.381).

59. Lewis Dr P.D., Backhouse D., Gous R.M. Photoperiod and oviposition time in broiler breeders. British Poultry Science, 2004, 45(4): 561-564 (doi: 10.1080/00071660412331286244).

60. Bhatti B.M. Distribution of oviposition times of hens in continuous darkness or continuous illumination. British Poultry Science, 1987, 28(2): 295-306 (doi: 10.1080/00071668708416962).

61. Duplaix M., Williams J., Mongin, P. Effects of an intermittent lighting schedule on the time of egg-laying and the levels of luteinizing hormone, progesterone and corticosterone in the plasma of the domestic hen. Journal of Endocrinology, 1981, 91(3): 375-383 (doi: 10.1677/joe.0.0910375).

62. Sauveur B., Mongin P. Performance of layers reared and/or kept under different 6-hour lightdark cycles. British Poultry Science, 1983, 24(3): 405-416 (doi: 10.1080/00071668308416755).

63. Mongin P. Food intake and oviposition by domestic fowl under symmetric skeleton photoperiods. British Poultry Science, 1980, 21(5): 389-394 (doi: 10.1080/00071668008416686).

64. Campo J.L., Gil M.G., Dávila S.G. Differences among white-, tinted-, and brown-egg laying hens for incidence of eggs laid on the floor and for oviposition time. Archiv für Geflügelkunde, 2007, 71(3): 105-109.

65. Washburn K.W., Potts P.L. Effect of strain and age on the relationship of oviposition time to shell strength. British Poultry Science, 1975, 16(6): 599-606 (doi: 10.1080/00071667508416235).

66. Halaj M. Study of dynamics of egg laying and properties during a day. Acta Zootechnica, 1974, 28: $162-171$.

67. Etches R.J., Petitte J.N., Anderson-Langmuir C.E. Interrelationship between the hypothalamus, pituitary gland, ovary, adrenal gland and the open period for LH release in the hen (Gallus domesticus). Journal of Experimental Zoology, 1984, 232(3): 501-511 (doi: 10.1002/jez.1402320317).

68. Etches R.J. The ovulatory cycle of the hen. Critical Reviews in Poultry Biology, 1990, 2(4): 293-318.

69. Lewis P.D., Perry G.C., Morris T.R. Effect of photoperiod on the mean oviposition time of two breeds of laying hen. British Poultry Science, 1995, 36(1): 33-37 (doi: 10.1080/00071669508417750).

70. Lewis P.D., Perry G.C., Morris T.R., English J. Supplementary dim light differentially influences sexual maturity, oviposition time, and melatonin rhythms in pullets. Poultry Science, 2001, 80(12): 1723-1728 (doi: 10.1093/ps/80.12.1723).

71. Tůmová E., Ledvinka Z. The effect of time of oviposition and age on egg weight, egg components weight and eggshell quality. Archiv für Geflügelkunde, 2009, 73(2): 110-115.

72. Naito M., Ueno T., Komiyama T., Miyazono Y. Oviposition times under various light-dark cycles in the domestic fowl. Japanese Poultry Science, 1980, 17(3): 146-150 (doi: 10.2141/jpsa.17.146).

73. Liou S.S., Biellier H.V. Light-dark cues entrain oviposition time in the chicken hen. International Journal of Biometeorology, 1987, 31(4): 285-292 (doi: 10.1007/bf02188939).

74. Wilson W.O. Photocontrol of oviposition in gallinaceous birds. Annals of the New York Academy of Science, 1964, 117(1): 194-202 (doi: 10.1111/j.1749-6632.1964.tb48173.x).

75. Bhatti B.M., Morris T.R. The relative importance of light and temperature as phase setting signals for oviposition in the fowl. British Poultry Science, 1977, 18(4): 391-395 (doi: 10.1080/00071667708416378).

76. Bhatti B.M., Morris T.R The relative importance of sunrise and sunset for entrainment of oviposition in the fowl. British Poultry Science, 1978, 19(3): 365-371 (doi: 10.1080/00071667808416488).

77. Bhatti B.M. Exogenous regulation of the time of oviposition in the domestic fowl. World's Poultry Science Journal, 1987, 43(2): 116-131 (doi: 10.1079/WPS19870009).

78. Tůmová E., Ebeid T. Effect of time of oviposition on egg quality characteristics in cages and in a litter housing system. Czech Journal of Animal Science, 2005, 50(3): 129-134 (doi: 10.17221/4006-CJAS).

79. Bhatti B.M., Morris T.R. Entrainment of oviposition in the fowl using light-dark cycles. British Poultry Science, 1978, 19(3): 333-340 (doi: 10.1080/00071667808416485).Emmans G.C., Fisher C. Problems in nutritional theory. In: Nutrient requirements of poultry and nutritional research /I. Fisher, K.N. Boorman (eds.). Butterworths, London, 1986: 9-39.

81. Johnston S.A., Gous R.M. An improved mathematical model of the ovulatory cycle of the laying hen. British Poultry Science, 2003, 44(5): 752-760 (doi: 10.1080/00071660310001643723).

82. Charvátová V., Tůmová E. Time of oviposition and egg composition: a review. Scientia Agriculturae Bohemica, 2010, 41(3): 190-195.

83. Hughes B.O., Gilbert A.B., Brown M.F. Categorisation and causes of abnormal egg shells: relationship with stress. British Poultry Science, 1986, 27(2): 325-337 (doi: 10.1080/00071668608416885).

84. Mills A.D., Nys Y., Gautron J., Zawadski J. Whitening of brown shelled eggs: individual variation and relationships with age, fearfulness, oviposition interval and stress. British Poultry Science, 1991, 32(1): 117-129 (doi: 10.1080/00071669108417333).

85. Brake J. Relationship of egg weight, specific gravity, and shell weight to time of oviposition and feeding in broiler breeders. Poultry Science, 1985, 64(11): 2037-2040 (doi: 10.3382/ps.0642037).

86. Lee K.D., Choi J.H. Interrelationships among time of oviposition, egg weight, shell weight, and rate of production of laying hens. Poultry Science, 1985, 64(12): 2256-2258 (doi: 10.3382/ps.0642256).

87. Hashiguchi M. Relationship of position of egg in sequence to eggshell quality in laying hen. Japanese Poultry Science, 1996, 33: 230-234 (doi: 10.2141/jpsa.33.230). 
88. Pavlovski Z., Vitorović D., Škrbić Z., Vračar S. Influence of limestone particle size in diets for hens and oviposition time on eggshell quality. Acta Veterinaria, Belgrade, 2000, 50(1): 37-42 (doi: 123456789/3).

89. Akif Boz M., Sarıca M., Yamak U.S. The effect of oviposition time on hatching traits of different chicken genotypes. European Poultry Science, 2014, 78 (doi: 10.1399/eps.2014.11).

90. Samiullah S., Roberts J., Chousalkar K. Oviposition time, flock age, and egg position in clutch in relation to brown eggshell color in laying hens. Poultry Science, 2016, 95(9): 2052-2057 (doi: $10.3382 / \mathrm{ps} /$ pew197).

91. Zakaria A.H., Plumstead P.W., Romero-Sanchez H., Leksrisompong N., Brake J. The effects of oviposition time on egg weight loss during storage and incubation, fertility, and hatchability of broiler hatching eggs. Poultry Science, 2009, 88(12): 2712-2717 (doi: 10.3382/ps.2009-00069).

92. Kryeziu A.J., Mestani N., Kamberi M., Berisha H. Effect of hen age and oviposition time on egg quality parameters. Proc. XIV European Symposium on the Quality of Eggs and Egg Products and XX European Symposium on the Quality of Poultry Meat. Leipzig, Germany, 2011: b-047 (doi: 10.13140/RG.2.1.1675.2808).

93. Tůmová E, Ledvinka Z., Skřivan M., Englmaierová M., Zita L. Effect of time of oviposition on egg quality in egg and meat type hens. Scientia Agriculturae Bohemica, 2008, 39(3): 269-272.

94. Harms R.H. Specific gravity of eggs and eggshell weight from commercial layers and broiler breeders in relation to time of oviposition. Poultry Science, 1991, 70(5): 1099-1104 (doi: 10.3382/ps.0701099).

95. Tůmová E., Skřivan M., Englmaierová M., Zita L. The effect of genotype, housing system and egg collection time on egg quality in egg type hens. Czech Journal of Animal Science, 2009, 54(1): 17-23 (doi: 10.17221/1736-CJAS).

96. Tůmová E., Zita L., Hubený M., Skřivan M., Ledvinka Z. The effect of oviposition time and genotype on egg quality characteristics in egg type hens. Czech Journal of Animal Science, 2007, 52(1): 26-30 (doi: 10.17221/2326-CJAS).

97. Yannakopoulos A.L., Tserveni-Gousi A.S., Nikokyris P.N. Egg composition as influenced by time of oviposition, egg weight, and age of hens. Archiv für Geflügelkunde, 1994, 58(5): 206-213.

98. Hrnčár C., Hässlerová M., Bujko J. The effect of oviposition time on egg quality parameters in Brown Leghorn, Oravka and Brahma hens. Scientific Papers: Animal Science and Biotechnologies, 2013, 46(1): 53-57.

99. Tůmová E., Gous R.M., Tyler N. Effect of hen age, environmental temperature, and oviposition time on egg shell quality and eggshell and serum mineral contents in laying and broiler breeder hens. Czech Journal of Animal Science, 2014, 59(9): 435-443 (doi: 10.17221/7655-CJAS).

100. Kebreab E., France J., Kwakkel R.P., Lesson S., Darmani Kuhi H., Dijkstra J. Development and evaluation of a dynamic model of calcium and phosphorus flows in layers. Poultry Science, 2009, 88(3): 680-689 (doi: 10.3382/ps.2008-00157).

101. Campo J.L., Escudero J. Relationship between egg-shell colour and two measurements of shell strength in the Vasca breed. British Poultry Science, 1984, 25(4): 467-476 (doi: 10.1080/00071668408454888).

102. Curtis P.A., Gardner F.A., Mellor D.B. A comparison of selected quality and compositional characteristics of brown and white shell eggs. II. Interior quality. Poultry Science, 1985, 64(2): 302-306 (doi: 10.3382/ps.0640302).

103. Jones D.R., Musgrove M.T., Anderson K.E., Thesmar H.S. Physical quality and composition of retail shell eggs. Poultry Science, 2010, 89(3): 582-587 (doi: 10.3382/ps.2009-00315).

104. Mertens K., Vaesen I., Loffel J., Kemps B., Kamers B., Perianu C., Zoons J., Darius P., Decuypere E., De Baerdemaeker J., De Ketelaere B. The transmission color value: A novel egg quality measure for recording shell color used for monitoring the stress and health status of a brown layer flock. Poultry Science, 2010, 89(3): 609-617 (doi: 10.3382/ps.2009-00261).

105. Ishikawa S., Suzuki K., Fukuda E., Arihara K., Yamamoto Y., Mukai T., Itoh M. Photodynamic antimicrobial activity of avian eggshell pigments. FEBS Letters, 2010, 584(4): 770-774 (doi: 10.1016/j.febslet.2009.12.041).

106. Abdalla M.A., Ochi E.B. Effect of laying hen's age and oviposition time on egg cholesterol contents. Science Letters, 2018, 6(1): 42-46.

107. Мяндметс Р., Хяммая Я., Руммель К. Длина циклов и пауз у белых и коричневых несушек. Птицеводство, 1993, 8: 14-15.

1ФНЦ Всероссийский научно-исследовательский и технологический институт птицеводства РАН,

Поступила в редакцию 8 октября 2019 года

141311 Россия, Московская обл., г. Сергиев Посад, ул. Птицеградская, 10, e-mail: alexk@vnitip.ru $\bowtie$, vnitip@vnitip.ru;

2ФГБОУ ВО Орловский государственный аграрный университет им. Н.В. Парахина,

302019 Россия, г. Орел, ул. Генерала Родина, 69,

e-mail: bvc5636@mail.ru, 


\title{
THE EFFECTS OF LIGHTING REGIMES ON THE OVIPOSITION TIME AND EGG QUALITY IN LAYING HENS
} (review)

\author{
A.Sh. Kavtarashvili', V.I. Fisinin', V.S. Buyarov², T.N. Kolokolnikova ${ }^{3}$
}

\begin{abstract}
${ }_{1}^{1}$ Federal Scientific Center All-Russian Research and Technological Poultry Institute RAS, 10, ul. Ptitsegradskaya, Sergiev Posad, Moscow Province, 141311 Russia, e-mail alexk@vnitip.ru ( $\square$ corresponding author), dp.vniipp@mail.ru,89267796966@yandex.ru;

2Parakhin Orel State Agrarian University, 69, ul. Generala Rodina, Orel, 302019 Russia, e-mail bvc5636@mail.ru; ${ }^{3}$ Siberian Research Institute of Poultry Farming - Branch of the Omsk Agrarian Scientific Center, 1, ul. 60 Let Pobedy, Morozovka, Omsk District, Omsk Province, 644555 Russia, e-mail kotani2009@mail.ru
\end{abstract} ORCID:

Kavtarashvili A.Sh. orcid.org/0000-0001-9108-1632

Fisinin V.I. orcid.org/0000-0003-0081-6336

The authors declare no conflict of interests

Received October 8, 2019

Buyarov V.S. orcid.org/0000-0002-6931-4353

doi: 10.15389/agrobiology.2019.6.1095eng

\section{Abstract}

Oviposition is a complex process where oviposition time (OT), clutch length (CL), and interval length (IL) are interrelated (B.G. Roy et al., 2014). The review presented highlights the effects of lighting regimes on the oviposition time in laying hens (Gallus gallus domsticus L.) in the relation with egg productivity and quality. OT is directly related to the ovulation time which, in turn, depends on the time of peak circulatory concentration of the luteinizing hormone (LG) released by the anterior pituitary (S.C. Wilson et al., 1984). In standard 24-hour light-dark cycles with single darkto-light switch oviposition occurs predominantly during the light phase (F. Noddegaard, 1998; G.A. Kirdyashkina et al., 2009) while in conditions of intermittent asymmetric lighting regimes it occurs during the «subjective day» period (P.D. Lewis et al., 1990; A.Sh. Kavtarashvili et al., 2002; A.Sh. Kavtarashvili, 2007). The most of daily laid eggs in a flock are laid during ca. 5-6 hours after the switch-on (A.H. Zakaria, 2005), corresponding to average OT 13-15 hours after the switch-off (K. Lillpers, 1991; P.H. Patterson, 1997; R.J. Etches, 1990; A.Sh. Kavtarashvili et al., 2019). Average OT is determined by complex interaction of «dawn» and «dusk» signals, the latter being the most influential in this case (S.S. Liou et al., 1987; B.M. Bhati et al., 1988). In 24-30-hour light-dark cycles every 1 hour of the cycle length with the same length of the light phase decreases average OT by 1.89-1.90 hours. The increase in the length of the light phase within given light-dark cycle by 1 hour shifts average OT by $0.26-0.27$ hours toward the «dusk» point. OT is known to affect egg quality. E.g. the weight of eggs laid in the morning is higher in compare to the eggs laid later (E. Tůmová et al., 2010; M. Akif Boz et al., 2014; S. Samiullah et al., 2016; A.J. Kryeziu et al., 2011). Some researchers (R.H. Harms, 1991; E. Tủmová et al., 2009) reported that egg weight, eggshell thickness and strength were higher in the eggs laid in the morning while in other studies (E. Tůmová et al., 2005, 2007; A.J. Kryeziu et al., 2011; C. Hrnčár et al., 2013) these parameters of egg quality were better in the eggs laid in the midday. The eggs laid in the morning were reported to have more intense brown eggshell pigmentation as compared to eggs laid in the midday (S. Samiullah et al., 2016; A.J. Kryeziu et al., 2011) and higher calcium content in the eggshell (E. Tůmová et al., 2014), $22.8 \%$ lower content of cholesterol (E. Tůmová et al., 2008; M.A. Abdalla et al., 2018), as well as lower phosphorus and magnesium levels (E. Tůmová et al., 2014). Hens that laid eggs preferably in the morning were reported to have longer $\mathrm{CL}$ and higher egg production in compare to hens which preferably lay eggs later. The heritability coefficient $\left(\mathrm{h}^{2}\right)$ of OT varies from 0.38 to 0.78 (K. Lillpers, 1991). The positive correlation $(r=0.54)$ between the CL and egg production was also reported (M. Bednarczyk et al., 2000; P. Miandmients et al., 1993). In view of the above mentioned average OT and $\mathrm{CL}$ can be reasonably included as the criteria into the selection programs for laying hens and broiler parental hens. In addition, the optimization of OT can improve egg quality and facilitate the rational organization of egg collection in the farms. The studies on the effects of lighting regimes on OT and egg quality were performed primarily in conditions of constant lighting schemes. The further research is necessary for the intermittent lighting regimes, on individually caged hens (with the recording of egg position within the clutches) and on hens kept in group cages.

Keywords: Gallus gallus domesticus, laying hens, lighting regime, oviposition time, egg quality. 